The following diagram, which is not, however, taken from the report, will explain the method :-

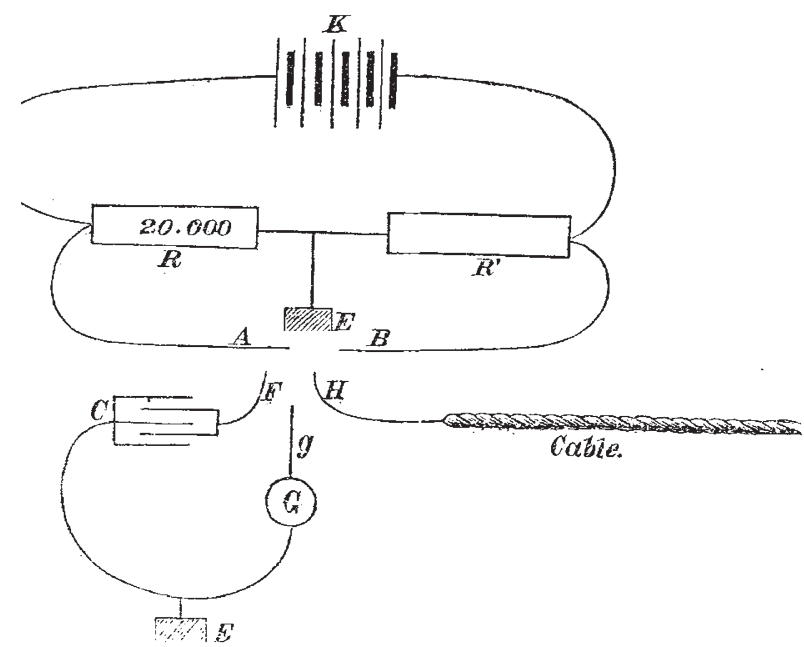

$K$, battery of 80 cells, well insulated; $R$ resistance of 20,000 units ; $R^{\prime}$ variable resistance; $\mathrm{C}$, condenser of 80 microfarads' capacity; G,
shunted galvanometer; $\mathrm{E}$, earth.

The condenser is electrified by bringing $\mathrm{F}$ and $\mathrm{A}$ into contact, and the cable by making contact between $H$ and B, for sufficiently long time to fully charge the cable. These contacts are then broken, and instantly after contact made between $F$ and $H$. This contact is maintained for five to ten seconds, when the additional contact with $g$ is made. The variable resistance is adjusted till this last contact produces no movement on the measuring instrument.

It was found that when the cable and condenser were charged to opposite potentials in the proportion of 1,615 to 20,000 no throw occurred, whence the deduction that the capacity of the cable was

$$
\frac{20000}{1615} \times 80 \text { microfarads, or }
$$

991 microfarads, and the length of the cable being 2,420 knots, this was equal to 0.409 of a microfarad per knot.

In concluding the report upon the electrical conditions of the Direct United States Cable, Sir William Thomson remarks: "I am glad to be able to say that my tests proved the cable to be in perfect condition as to insulation, and showed its electrostatic capacity and copper resistance to be so small as to give it a power of transmitting messages, which, for a transatlantic cable of so great a length, is a very remarkable as well as valuable achievement." This article would be exceeding its purpose if it were to include inquiry into the present position of Atlantic Telegraphy; but it is a mark of great progress in electrical engineering and cable manufacture that a cable of such length as 2,420 miles can be delivered up to the company working it in a perfect electrical condition. This has not been the case in earlier transatlantic attempts; and some idea may be formed by the general reader of the care required to bring about this end, when it is known that a small hole, smaller in size than the finest pin-hole, in any portion of the two thousand miles length of gutta-percha covering would render the electrical conditions of the cable imperfect.

\section{THE CLIMATIC CHARACTERISTICS OF WINDS AS DEPENDENT ON THEIR ORIGIN 1}

$\mathrm{F}^{\mathrm{F}}$ the climatic characteristics of winds the most important are, primarily, their temperature, and, secondarily, their moisture. The general occurrence of

${ }^{x}$ Ueber die Abhängigkeit des KTimatischen Charakters der Winde von ihrem Ursprunge. Von Dr. W. Köppen. (St. Petersburg, 1874.) certain characteristics, especially when more strongly marked, with particular directions of the wind, experience soon forces on our attention, and much labour has been bestowed, particularly by Dove, in grouping the winds simply according to their directions, and calculating the mean atmospheric pressure, temperature, humidity, cloud, and rainfall, for each of the directions. Interesting and to some extent valuable results have been obtained from these inquiries; results, it must, however, be added, far from being commensurate with the enormous labour expended in arriving at them. But in extending this line of research into such regions as Western Norway, Faio, Iceland, Newfoundland, and the Azores, its unsatisfactoriness soon becomes evident ; and the further consideration that the climatic qualities of a particular wind repeatedly differ widely from its general character, makes it evident that a climatic inquiry which groups the winds merely according to their direction does not proceed from a scientific basis.

A striking case, showing a great deviation from the gene. ral qualities of a wind, occurred during the great Edinburgh hurricane of the 24th of January, 1868 , on which occasion the wind remained persistentiy in the south for several hours, and possessed a coldness and a dryness which were truly polar. The qualities of this south wind are readily explained by the limited area of high pressure, which lay immediately to the south-eastward of Scotland at the time, out of which this wind blew. As the barometer continued to fall, the wind ultimately veered to S.W. and W., and the temperature presented the unusual phenomenon of rapidly rising with a change of the wind into westward. The point to be noted here is, that as long as the wind was connected immediately with the circumscribed area of high pressure it was cold and dry, but when it was involved in the area of low pressure it became mild and moist. This relation between the climatic qualities of a wind and the state of the pressure is a vital point in atmospheric physics, and to Dr. Köppen belongs the merit of applying the principle in inatgurating a new method of inquiring into the climatic characteristics of the different winds by referring each wind-observation to the system of atmospheric pressure with which it is at the moment immediately connected.

If we examine weather-charts representing a large portion of the earth's surface, such as those published in the Fournal of the Scottish Meteorological Society, vol. ii. p. 198 , two distinct systems of pressure are seen, which change their position and form from day to day, one indicated by isobars inclosing spaces of low pressure, into which the winds all round blow vorticosely in the northern herrisphere in a direction contrary to that of the hands of a watch, and the other by isobars inclosing areas of high pressure, out of which the winds blow on all sides, but in opposite directions to those assumed in blowing inwards upon a space of low pressure. The former are usually called cyclones, and the latter anticyclones. Not only do the direction of the winds within the areas of cyclones and anticyclones respectively differ from each other, but the temperature and humidity of the winds connected with each have certain well-marked characteristics. A south-east wind at St. Petersburg, for instance, blowing in immediate connection with a cyclone, comes from the south and south-west, that is, from the southwest of Russia or from Germany ; whereas a south-east wind in immediate connection with an anticyclone comes from the east, that is, either from the east of Russia or from the White Sea, and consequently these two southeast winds are markedly different in their climatic qualities from each other.

Dr. Köppen has compared the temperature, humidity, and other weather conditions at St. Petersburg each day for 1872 and 1873 with daily weather-charts constructed for the whole of Europe, and separated each of the eight winds (N., N.E., E., \&C.) and calms into the following 
four classes:-I. Those which occur when the isobar, passing through St. Petersburg, bounds a space of low pressure, or when St. Petersburg is included within the area of a cyclone; 2 . When the isobar bounds the space of high pressure, or is within the area of an anticyclone; 3. When it is in the calm centre of an anticyclone; and 4. When the isobar does not, at least on the map of Europe, inclose a space, but stretches away in a line which is either straight or irregularly waved. This division is carried out as regards the two great divisions of the year, viz, the cold half, extending from October to March, and the warm half from April to September.

The following will indicate the importance of the results arrived at:-1. During the cold half of the year, northerly winds (N.E. and N.) when connected with a cyclone have the pressure 0.370 inch below the average, the temperature $2^{\circ} \cdot 3$ above the average, the relative humidity 90 , and the sky all but completely covered with cloud; with an anticyclone, pressure is $0.27 \mathrm{I}$ inch above the average, temperature $8^{\circ} .6$ below the average, humidity 84 , and sky only three-fourths covered; and with a straight indeterminate isobar, pressure is $0^{\circ} 20 \mathrm{I}$ inch above the average, temperature $5^{\circ} .8$ below the average, humidity 89 , and sky less than three-fourths covered. 2. During the warm half of the year, northerly winds connected with a cyclone have pressure 0.192 inch, and temperature $5^{\circ} .4$ below the average, humidity 87 , and cloud 8 ; with an anticylone pressure is 0.206 inch, and temperature 0.5 above the average, humidity 75 , and cloud 4 ; and with straight indeterminate isobars, pressure is 0.104 inch above, and temperature $3^{\circ} 4$ below the average, humidity 76 , and cloud 5 .

As regards the S.E. wind, with a cyclone the temperature is $7^{\circ} \cdot 2$ above the average in winter, but only $1^{0.8}$ in summer ; and with an anticyclone, $4^{\circ} \circ$ below the average in winter, but $2^{\circ} \cdot 5$ above it in summer. Again, with straight isobars, S.E., S., and S.W. winds have in winter a temperature $7^{\circ} 7$ above the average, humidity 93 , and cloud 9 ; but in summer the figures are $5^{\circ} 2,82$, and 6 respectively. One of the most suggestive results is that obtained from the examination of the anticyclone in summer, particularly as regards its calm central space. In the periphery of the anticyclone where winds prevail, the cloud accompanying the different winds varies from 3 with S.W. to 5 with E. winds, but in the calm central space the amount is only 2 ; in other words, the space covered by the anticyclone is remarkable for the clearness of its sky, and the central portion is the clearest. Owing to the strong insolation which takes place under these circumstances, the temperature of the whole space covered by the anticyclone is raised $2^{\circ} \cdot \mathrm{I}$ above the average ; with northerly winds (N.E., N., and N.W.) the excess is, as might be expected, small, being only $0^{\circ} .5$, but with S, and S.W. winds the average excess is $4^{\circ} \mathrm{I}$. The excess in the calm centre is only $\mathrm{I}^{\circ} 3$, which is smaller than the excess which accompanies winds from the E., S.E., S., S.W., and W. points of the compass.

In a review of the weather of Europe during I $868,{ }^{*} \mathrm{Mr}$. Buchan drew attention to the anticyclone which overspread a considerable portion of Europe from the 2nd to 4th August, as the immediate cause of the hot weather experienced in Great Britain at the time, and which he regarded as the simple result of the widespread high pressure, the comparatively calm atmosphere, the clear sky, the dry air, and the strong insolation which accompanied these conditions. At the same time, to the west, north, and south-east, pressures were low, the sky clouded, and much rain fell. Since the wind blew out from the anticyclone in all directions, - E. and S.E. winds in Great Britain and France, W. in Austria, and S.W. in Sweden and W. in Russia,-without diminishing the high pressure of the anticyclone, it was suggested that

* Atlas Météorologique de l'Observatoira Impérial, Année r868, D. 39. Paris, $x 869$. the high pressure was maintained by air-currents ascending from the regions of low pressure to the west, north, and south-east, and thence flowing as upper currents towards and then down upon the region of the anticyclone. In connection with this point Clement Ley has made some valuable observations on the upper currents of the atmosphere, showing that they flow outwards from the centre of the cyclone, and inwards towards the anticyclone. If this view be correct, the centre of the anticyclone must necessarily be filled with a slowly descending current.

Now, it will be observed from Dr. Köppen's inquiry that the centre of the anticyclone is the clearest, on leaving which and entering the regions in which winds blow, the sky becomes more clouded-a result strictly in accordance with a descending current over the calm region of the centre. Again, in the calm centre the temperature is lower than round the periphery (except where N.E., N., and N.W. winds prevail, bringing air current: from colder regions, and therefore of a lower temperature), a result admitting of explanation only on the supposition of a descending current within the central space, since, were there no descending current, the temperature would be hottest in the centre where the atmosphere is clearest and the air stillest.

We are now, thanks to Dr. Köppen, put in possession of a truly scientific method of discussing wind-observations in their climatic relations, the value of which will be the more apparent when the observations of places in different parts of Europe have been discussed in accordance with it. What is now wanted, as regards the diffcult but vital question of the observation of the wind, is that truly comparable anemometers be procurable, and that they be placed in situations and positions so that they may fairly record the direction, velocity, and pressure of the air-currents which pass over the district where they are placed.

\section{SCIENCE IN GERMANY}

\section{(From a German Corresponatent)}

M VON JOLLY, in Munich, has recently constructed M. an apparatus for gas-determination by absorption. Its arrangernent is, in general, similar to that of Frankland's apparatus, but it is distinguished from this, as from all other apparatus nitherto used for gas analysis, by the principle of measurement that is peculiar to it. Measurement is made, not of the changes of volume, which, for example, the air undergoes through absorption of carbonic acid and of oxygen, but of changes of pressure, the volume remaining the same. All the air-quantities to be measured are brought to the same volume, through corresponding change of pressure, in a measuring vessel, the contents of which must not be known; while a temperature of $0^{\circ}$ is produced by surrounding the measuring vessel with snow or ice. Thus, each time the tension is measured under which the air-quantity to be considered assumes that constant volume, before and after absorption of a portion of the mixture. This process has various advantages over those hitherto in use. The calculation of the gas-volumes at normal pressure and temperature is rendered superfluous; the number of separate observations required is diminished.

M. Jolly's apparatus is represented in the annexed figure. A is the absorption bell-jar ; it is of nearly IOO c.c. capacity. It is open below, and stands in a pneumatic trough. $B$ is the cylindrical measuring vessel of equal capacity with the absorption jar. By means of a $T$-shaped perforated glass cock $h$, the vessels $A$ and $B$ can be connected; they can also be put in communication with the atmosphere by the capillary tube $g . \quad$ B is connected by means of a capillary tube, with a wide glass tube $\mathrm{E}$. At $f$ there is, within the curve, where the capillary tube opens, a small tongue of dark glass, 1 to $2 \mathrm{~mm}$. long, with 